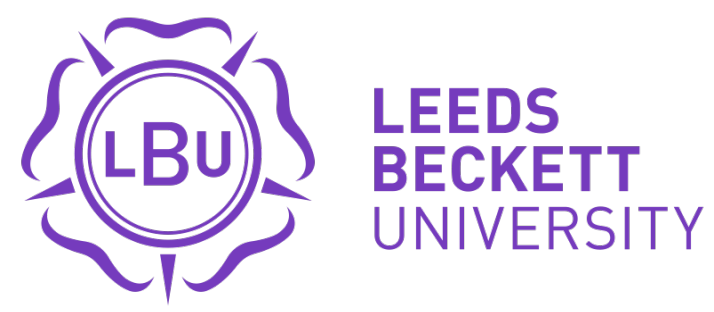

Citation:

Asquith, SL and Wang, X and Quintana, DS and Abraham, A (2020) Predictors of Creativity in Young People: Using Frequentist and Bayesian Approaches in Estimating the Importance of Individual and Contextual Factors. Psychology of Aesthetics, Creativity, and the Arts. ISSN 1931-3896 DOI: https://doi.org/10.1037/aca0000322

Link to Leeds Beckett Repository record:

http://eprints.leedsbeckett.ac.uk/6946/

Document Version:

Article

The aim of the Leeds Beckett Repository is to provide open access to our research, as required by funder policies and permitted by publishers and copyright law.

The Leeds Beckett repository holds a wide range of publications, each of which has been checked for copyright and the relevant embargo period has been applied by the Research Services team.

We operate on a standard take-down policy. If you are the author or publisher of an output and you would like it removed from the repository, please contact us and we will investigate on a case-by-case basis.

Each thesis in the repository has been cleared where necessary by the author for third party copyright. If you would like a thesis to be removed from the repository or believe there is an issue with copyright, please contact us on openaccess@leedsbeckett.ac.uk and we will investigate on a case-by-case basis. 
Predictors of Creativity in Young People: Using Frequentist and Bayesian Approaches in Estimating the Importance of Individual and Contextual Factors

Sarah L. Asquith and Xu Wang

Leed s Beckett University

Daniel S. Quintana

University of Oslo and Oslo University Hospital

Anna Abraham

University of Georgia

Author Note:

Sarah L. Asquith, Leeds School of Social Sciences, Leeds Beckett University, Leeds, UK; Xu Wang, Leed s School of Social Sciences, Leed s Beckett University, Leeds, UK;

Daniel S. Quintana, Norwegian Centre for Mental Disorders Research (NORMENT), Division of Mental Health and Addiction, University of Oslo, and Oslo University Hospital, Oslo, Norway; Anna Abraham, Torrance Center for Creativity and Talent Development, Department of Educational Psychology, UKCollege of Education, University of Georgia, Athens, USA.

Correspondence concerning this article should be addressed to Sarah L. Asquith, Leeds School of Social Sciences, Leeds Beckett University, City Campus, Leeds LS1 3HE, UK. E-mail: s.l.asquith@ leedsbeckett.ac.uk 


\begin{abstract}
The development of creativity in young children has been studied extensively, but relatively few studies have examined the period of adolescence and emerging adulthood in relation to creative potential. The present study employs a combination of frequentist and Bayesian analyses to evaluate the impact of individual factors (e.g., IQ) and contextual factors (e.g., pursuit of creative hobbies) on creative ideation in three cohorts of young people aged 14-20 years. Measures of divergent thinking, specifically the Alternate Uses Task (AUT) and the Overcoming Knowledge Constraints Task, were used to this end. Openness to aesthetic and imaginative experience was the strongest predictor of creative potential for the three AUT measures. Moreover, Bayesian hypothesis testing revealed that the best predictive model for AUT ideational fluency and AUT overall originality was one that included only Openness, whereas the best predictive model for AUT peak originality, or the propensity to generate highly original responses, included Openness, as well as IQ and Engagement in Creative Hobbies. No group differences in creative potential were found between the three age cohorts (aged 14-15, 16-17, and 18-20). The study not only confirms the importance of openness to aesthetic and imaginative experience as a predictor of creative potential in adolescents and young adults, but also indicates the necessity to consider the combined and differentiated impact of individual and contextual factors in different facets of creative ideation.
\end{abstract}

Keywords: creative potential, personality, intelligence, creative hobbies, adolescents and young adults 


\section{Predictors of Creativity in Young People: Using Frequentist and Bayesian Approaches in Estimating the Importance of Individual and Contextual Factors}

The development of creativity in the form of creative potential has been studied extensively in young children (Runco \& Albert, 1986; G. J. W. Smith \& Carlsson, 1983; Torrance, 1968), but fewer studies have examined it in adolescents and young adults. Models of creativity have proposed that this ability arises from the interaction of a number of different factors including intelligence, personality, executive functions, motivation, and the environment (e.g., Amabile, 1996; Barbot, Lubart, \& Besançon, 2016; Sternberg \& Lubart, 1992). However, complex interactions between two of more of these factors have been examined in relatively few studies (Davis, Kaufman, \& McClure, 2011; Deng, Wang, \& Zhao, 2016; Nusbaum \& Silvia, 2011). The current study examines creative potential in young people aged between 14 and 20 and the impact of specific individual and contextual factors associated with it. Tasks of divergent thinking, or the ability to generate multiple responses to an open-ended problem (Runco \& Acar, 2012), were used to this end.

\section{The Development of Creativity}

The standard definition of creativity comprises two key aspects: novelty or originality, and usefulness or appropriateness (Runco \& Jaeger, 2012). Divergent thinking is an aspect of creative cognition that has been widely studied (Reiter-Palmon, Forthmann, \& Barbot, 2019), and involves the generation of multiple solutions to a given problem or stimulus (Guilford, 1967). As such it is a measure of idea generation which is a critical component of creativity (Reiter-Palmon et al., 2019) and is predictive of creative achievement (Guilford, 1966; Kim, 2008; Plucker, 1999). Divergent thinking tasks may be used with young and older participants (McCrae, Arenberg, \& Costa, 1987; Torrance, 1968), and are commonly scored 
on dimensions of fluency, or the quantity of ideas generated, flexibility, or the number of different categories of responses, and originality, or the uncommonness of the responses (Guilford, 1967; Reiter-Palmon et al., 2019).

The development of creativity occurs across the life span and may be expressed in different forms at different stages of life. Patterns of growth, stability and decline are nonlinear and depend on the type of creativity that is being examined (Hui, He \& Wong, 2019). Creative potential measured through standardised tests develops through childhood to maturity in adulthood (McCrae et al., 1987; Torrance, 1968) but does not follow a simple linear trajectory. Torrance (1968) identified slumps on entry into school, $4^{\text {th }}$ grade, and $6^{\text {th }} /$ $7^{\text {th }}$ grade, and others have found dips and peaks in adolescence (see Barbot et al., 2016, for a review). A number of factors have been associated with these 'slumps and bumps'. These include cognitive and biological changes, such as the stages of cognitive development, and the development of the prefrontal cortex as well as social and environmental factors, such as the need for acceptance in the peer group, and pedagogical approach (Barbot et al., 2016; Besançon \& Lubart, 2008; Gralewski, Lebuda, Gajda, Jankowska, \& Wiśniewska, 2016; He \& Wong, 2015). Although many studies have examined the development of creativity in children from entry into school through to mid-adolescence, relatively few have examined it in young people in the periods of adolescence and emerging adulthood. Gralewski et al. (2016) studied creative potential in children and young people (4-21 years of age) and found significant decreases in creativity from age 15 to 17 before rising again. They related the dip in creativity to the maturation-based changes in the brain as well as to the development of identity at this age (Erikson, 1968) and the need to adjust to social norms, which may have a dampening effect on originality. Jastrzębska and Limont (2017) found that creative potential increased in students from ages 7 to 18 , but that there were plateaus and mini-plateaus as well as drops. For instance, a drop in the scores of 16-year olds coincided with the transition to 
secondary school. Kleibeuker, De Dreu, and Crone (2013) examined creativity in four groups of adolescents and young adults, aged 12-13, 15-16, 18-19, and 25-30. With regard to divergent thinking, there were no group differences in fluency and flexibility, but originality was shown to increase with age. Creative potential seems therefore generally to increase over the period of adolescence through to adulthood but with sporadic temporary declines, which vary according to the type of task and the aspect of creativity that is being measured.

\section{Predictors of Creativity: Individual Factors}

A large body of research has investigated personality factors that are predictive of creativity and the most consistent finding to date is that 'openness to experience' is the most relevant trait in this regard. Openness to experience reflects imagination, aesthetic sensitivity, attentiveness to emotional states, intellectual curiosity, and interest in new experiences and questioning conventional values (Costa \& McCrae, 1985). It is a highly reliable positive predictor of creativity, whether measured by creative potential, creative achievement, self-ratings or external ratings (Puryear, Kettler, \& Rinn, 2017). Although openness has been consistently associated with higher creativity, its importance may vary by domain, being more strongly related to creativity in the arts, than the sciences (de Manzano \& Ullén, 2018; Feist, 1998; Hong, Peng, \& O'Neil, 2014). When the two aspects of openness to experience are considered, 'openness', or engagement with aesthetics, perception and fantasy, and 'intellect', or engagement with abstract and semantic information, the former predicts achievement in the arts, whereas the latter predicts achievement in the sciences (Kaufman et al., 2016). The focus in the present study is limited to openness to aesthetic and imaginative experience.

The degree to which creativity and intelligence are related has been the subject of much study. Threshold theory (Guilford, 1967) holds that intelligence is necessary, but not 
sufficient, for creativity, such that creativity and intelligence are related only up to a certain point, suggested to be an IQ of 120, and beyond that, it is possible to be highly intelligent, without being highly creative. Kim's (2005) meta-analysis indicated a small positive relationship $(r=.17)$ between creativity and intelligence, but no evidence in support of the threshold hypothesis. In contrast, more recent studies have adopted different methodological approaches to studying the relationship and have found evidence to support the existence of a threshold (Jauk, Benedek, Dunst, \& Neubauer, 2013; Karwowski et al., 2016). For instance, using segmented regression analysis, Jauk et al. (2013) found that the IQ threshold differed depending on the divergent thinking measure in question, such that there was a low threshold (IQ score of 85) for creative potential as measured by fluency in a divergent thinking task, but higher thresholds (IQ scores of 102 and 120) for originality as measured by the top 2 ideas, or by many original ideas. It has also been suggested that the correlations between creativity and intelligence may be larger than found in Kim's (2005) meta-analysis, depending on the way in which creative potential is scored, and the statistical modelling approach (Benedek, Jauk, Sommer, Arendasy, \& Neubauer, 2014; Jauk, Benedek, \& Neubauer, 2014; Silvia, 2008b). Overall, the literature indicates that there is a positive relationship between creativity and intelligence, but the size of the correlation and the extent to which thresholds apply varies depending on the creativity measure, the scoring method and statistical approach, and the sample under study.

The conditional threshold hypothesis (Harris, Williamson \& Carter, 2019) offers a new perspective on the relationship between creativity and intelligence. It proposes that the relationship between creative achievement and intelligence is moderated by other variables such as individual differences or environmental factors. In contrast to the classic threshold hypothesis (Guilford, 1967), the conditional threshold hypothesis proposes an inverted relationship, such that above the threshold, the relationship between creative achievement and 
intelligence is stronger in people with high levels of these factors. Specifically, Harris et al.'s study (2019) found that the relationship between creative achievement and intelligence was stronger in people with high levels of openness compared to moderate or low levels, and that for this group, the strength of the relationship increased at higher levels of intelligence. Furthermore, in line with Kaufman et al.'s study (2016), the two aspects of openness, aesthetic openness and intellect, were differentially related to domain-specific achievement, such that achievement in the arts required high levels of aesthetic openness, and in the sciences, high levels of intellect.

Executive functions is a term used to describe a set of mental processes that include working memory, cognitive flexibility, and inhibitory control (Diamond, 2013). Working memory is the ability to maintain, update and manipulate information in one's mind in service of a goal. Cognitive flexibility reflects the ability to switch to new tasks or rule sets and to consider new perspectives. Inhibitory control is the ability to suppress unwanted thoughts or responses and focus one's attention, emotions, thoughts and behaviour. The complex relation between executive functions and creative potential is one that is receiving increasingly more focus. Studies of the relationship between divergent thinking and working memory have found mixed results (Benedek et al., 2014; Smeekens \& Kane, 2016). Studies that have examined creative thinking more broadly have suggested mechanisms by which working memory and creativity are related: by directly allowing for persistence and focused attention (De Dreu, Nijstad, Baas, Wolsink, \& Roskes, 2012) or indirectly through intelligence and associative fluency (Lee \& Therriault, 2013).

The relationship between creativity and inhibitory control is also a complex one. Carson, Peterson, and Higgins (2003) found that greater creativity in terms of high originality scores in a divergent thinking task and high scores on the creative achievement task were associated with lower levels of latent inhibition, which is the ability "to screen from current 
attentional focus stimuli previously experienced as irrelevant" (p. 499). In contrast, Benedek, Franz, Heene, and Neubauer (2012) found a positive correlation between inhibition and selfreport measures of creativity, as well as ideational fluency and flexibility in a divergent thinking task. The literature therefore suggests that creativity is associated with both lower and higher inhibitory control. One way to accommodate both these perspectives is to consider that creative people are able to focus or defocus their attention as required by the task (Zabelina \& Ganis, 2018; Zabelina \& Robinson, 2010). Others have suggested (Abraham, 2014a, 2014b; Carson, 2011) that the relationship between creativity and inhibition may take the form of an inverted-U function in which a mild disruption of inhibition may enhance creativity, but severe dysfunction is associated with poor creative performance.

\section{Predictors of Creativity: Contextual Factors}

Many theoretical models recognise that creativity is affected not only by individual factors but also by factors within the environment, which may provide motivation, stimulation, evaluation, and resources (Amabile, 1996; Sternberg \& Lubart, 1996). Environmental or contextual factors that have been shown to affect creativity include working environment and organisational climate, culture, family environment, socioeconomic status, and school environment (Besançon \& Lubart, 2008; Deng et al., 2016; Hunter, Bedell, \& Mumford, 2007; Ma, 2009; Niu, 2007). Adolescents and emerging adults become increasingly independent with age in terms of how they spend their free time and may choose to engage in a range of activities including hobbies, sports and physical activity, socialising with friends, and so on. Choice of leisure activities has been investigated in relation to a range of outcomes including academic achievement, socio-emotional outcomes, and wellbeing (Bartko \& Eccles, 2003; Feldman \& Matjasko, 2005; Goldstein, 2011). Extracurricular activities, including membership of arts and academic clubs is associated with 
creativity in college students (Cotter, Pretz, \& Kaufman, 2016), and what young people choose to do out of school may display more creativity than what they do in school (Runco, Acar, \& Cayirdag, 2017). It may therefore be informative to investigate young people's choice of leisure activities and its relationship with creative potential.

\section{The Current Study}

The aim of the current study was to explore the predictors of creativity in young people, aged 14-20, in secondary school and the first year of university. The study focuses on creative potential, as the participants are young, and have had limited opportunities for creative achievement. Two creativity tasks which varied in relation to the types of creative cognitive operations being engaged were included (see Abraham \& Windmann, 2007; Abraham, 2014b) thereby allowing for a broader assessment of creative potential. The predictors included both individual differences, specifically intelligence and personality, and contextual factors in the form of leisure activities. Intelligence, openness to aesthetic and imaginative experience, working memory, inhibitory control and engagement in creative hobbies were expected to positively predict creative potential. The approach is similar to other studies in the field which have sought to examine the relative influence of different variables on creativity (e.g. Batey, Chamorro-Premuzic \& Furnham, 2007; Davis et al., 2011; Furnham, 2015). A combination of frequentist and Bayesian approaches were employed in the data analyses.

\section{Method}

\section{Participants}

Participants were recruited in three cohorts (aged 14-15, 16-17, and 18-20), $(\mathrm{N}=409$, male $=80$, female $=328$, non-binary $=1)$. Participants in cohort $1\left(\mathrm{M}_{\mathrm{age}}=14.91, \mathrm{SD}=0.32\right)$ and cohort $2\left(\mathrm{M}_{\mathrm{age}}=16.91, \mathrm{SD}=0.41\right)$ were recruited from secondary schools and colleges 
in West and North Yorkshire, UK. All schools and colleges in five towns and cities in the region were contacted to recruit participants for the two youngest age groups, and 11 institutions out of 132 agreed to take part (seven for cohort 1 and the same seven and a further four schools and colleges for cohort 2). The schools were offered a workshop for their students on creativity, research methods, or applying to study at university, in return for their involvement. Cohort $3\left(\mathrm{M}_{\mathrm{age}}=19.00, \mathrm{SD}=0.59\right)$ was recruited from first year university students at the lead author's institution. The sample was predominantly female $(80 \%)$. This was largely due to gender bias in students of Psychology: in cohort 3 the majority were Psychology undergraduates, and in cohorts 1 and 2, it was typically Psychology teachers who responded and arranged for their Psychology classes to take part (two out of seven schools in cohort 1 , and ten out of 11 schools and colleges in cohort 2). In addition, two of the schools that responded were single sex girls' schools. Participants had the opportunity to enter a prize draw for cinema vouchers, and university students on the Psychology undergraduate degree could opt for course credit. The sociodemographic information associated with the samples is presented in Table S1 and the findings in relation to the same are presented in the supplemental material.

\section{Materials}

Creativity task 1. The Alternate Uses Task (AUT) (Guilford, Christensen, Merrifield, \& Wilson, 1960) requires participants to generate many different uses for a common object. Participants were given two minutes per item to think of uses for three items (newspaper, shoe, and paperclip) and were instructed to think of uses which were different from their customary use. The responses for all age groups were scored together and three dependent measures were derived from the responses. Fluency was calculated as the average number of valid responses generated across the three items. Overall originality was

calculated based on the relative frequency of the uses across participants (Abraham, Asquith, 
Ahmed, \& Bourisly, 2019; Runco, Okuda, \& Thurston, 1987). For example, if a use is given by 45 participants out of 409 , the relative frequency is 0.11 . The relative frequency of each participant's uses was totalled and divided by the fluency score to give an average relative frequency, and this was subtracted from 1 so that a high score relates to high originality. The scores were averaged across the three items. The data for cohorts 1 and 2 was highly skewed ( $z$-score $=-10.61$ and -18.44 respectively), and so the data was transformed for all three cohorts, using a reverse inverse approach, overall originality $=1 /$ ( 1 - average originality index). Peak originality was calculated as the number of responses given by the participant that were generated by $10 \%$ or less of the participants in the sample (Abraham et al., 2019).

Creativity task 2. The overcoming knowledge constraints task $(\mathrm{OKC})$ requires participants to come up with a new idea for a toy and to draw it (Abraham \& Windmann, 2007; S. M. Smith, Ward, \& Schumacher, 1993). Before they do so, they are shown three examples of novel toys invented by others, each of which contains three common elements, a ball, the use of electronics, and the need for physical exertion. The toys are scored based on how many of these three elements they contain, and possible scores range from 0 to 3 . For ease of interpretation the scores were reversed so that a higher score (OKC raw score) means a greater ability to inhibit the task-relevant information in the form of the presented examples (Abraham, 2014b). Relatively few participants (29/390) achieved a score of 3, so the OKC raw score was recoded into a binary variable, OKC (scores of 0 and $1=0$, scores of 2 and $3=$ 1).

Personality. A ten-item version of the Big Five Inventory (John, Donahue, \& Kentle, 1991) was used (BFI-10; Rammstedt \& John, 2007) to reduce testing demands on the young participants. There are two items for each trait (e.g., 'I see myself as someone who... is outgoing, sociable'). Participants respond on a 5-point scale (1 = disagree strongly, $5=$ agree strongly), resulting in scores of 2-10 for extraversion, agreeableness, 
conscientiousness, neuroticism and openness. Scores from the BFI-10 have been shown to have acceptable correlations with the BFI and acceptable test-retest reliability (Rammstedt \& John, 2007). The wording of one of the two items for openness '...has few artistic interests' was changed to 'has lots of artistic interests' as the negative phrasing may have been difficult to understand within young samples in relation to the response scale. The wording of the other item for openness was 'has an active imagination'. Cronbach's alpha for openness was .61, which is acceptable for a two-item scale (Brailovskaia \& Margraf, 2018; Götz, Ebert, \& Rentfrow, 2018; Whaite, Shensa, Sidani, Colditz, \& Primack, 2018). In taking a 2-item scale, we assess only the aesthetic and imaginative aspects of openness to experience.

Intelligence. A nine-item short form of Raven's Standard Progressive Matrices (SPM; Raven, Court, \& Raven, 1995) was used (Bilker et al., 2012) to reduce testing demands on the young participants. The short form was developed to reduce administration time while providing good psychometric properties and correlations to the 60 -item form equal to other abbreviated forms (Bilker et al., 2012). The obtained score was translated into an IQ score using the table developed by Jensen, Saccuzzo, and Larson (1988).

Executive functions. Two tasks were used, one to assess working memory (the digit span task from the WAIS; Wechsler, 2010) and one to assess response inhibition (the Hayling Sentence Completion Test) (Burgess \& Shallice, 1997). The digit span task has three parts, which ask the participants to respond putting a sequence of digits into a specified order; forwards, i.e. in the order in which they were read out, which measures short term memory capacity; backwards, i.e. reversing the order in which they were read out, which measures working memory; and in sequence, i.e. reordering them into the correct numerical sequence, which measures the ability to manipulate information in working memory. Participants in cohorts 1 and 2 were asked to complete the forwards and backwards tasks, and participants in cohort 3 completed all three. The longest digit span forwards (LDSF) and the longest digit 
span backwards (LDSB) were calculated for all cohorts. The longest digit span sequence (LDSS) was calculated for cohort 3. The mean scores were higher than the UK norms for the LDSB scores, (Wechsler, 2010) which suggests that written rather than verbal responses may give some advantage (see supplemental material for cohort-specific information).

The Hayling Sentence Completion Test (Burgess \& Shallice, 1997) is a response suppression test that has two parts, both containing 15 items. The first part is a sensible sentence completion task, in which participants must complete an incomplete sentence (e.g., The old house will be torn __.) with a word that fits (e.g., down). The second part is an unconnected sentence completion task, in which participants must complete the incomplete sentence with a word that is completely semantically unconnected (e.g., banana). The responses to part 2 were scored in line with the guidance (Burgess \& Shallice, 1997) as falling within one of three categories: a correct response, when the word was completely unrelated to the sentence; a category A error, when the word completed the sentence in a sensible way (e.g. 'the dough was put in the hot oven'); and a category B error, when the word was connected to the meaning of the sentence in some way (e.g. 'the dough was put in the hot sink'). The number of category A and B errors was summed and the raw score was then translated to a scaled score $(1-8$, where $8=\operatorname{good}$ (no errors), and $1=$ impaired). A very high percentage of the participants, $97.7 \%$, achieved scores of $6-8$, with $58 \%$ achieving the maximum score of 8 . Owing to these ceiling effects, this error measure was not included in the data analyses.

Leisure Questionnaire. This questionnaire (included in supplemental material) was developed by the research team to find out how participants spent their spare time. It was adapted from examples of questionnaires within the leisure literature (Ábrahám, Velenczei, \& Szabo, 2012; Badia, Orgaz, Verdugo, \& Ullan, 2013; Jopp \& Hertzog, 2010; Passmore \& French, 2001). Participants were asked about four main areas: creative hobbies and interests, 
sports and physical activity, socialising, and relaxing. Participants were asked to indicate how often over the last month they had done each activity: from never, less than once a week, 1-2 days a week, 3-4 days a week, 5-6 days a week to every day. A score for engagement in creative hobbies was calculated based on the number of creative hobbies ticked by the participants, and how often they engaged in those hobbies (less than once a week $=0.5,1-2$ days a week $=1.5,3-4$ days a week $=3.5,5-6$ days a week $=5.5$ and every day $=7$ ). A score for engagement in sports and physical activity was calculated in the same way.

\section{Procedure}

Participants took part within group sessions in schools and colleges or at the university, between October 2016 and March 2017. Permission for the study was granted by the Local Research Ethics Committee at the lead author's institution. For the first two age groups, information sheets were provided both for the students, and for their parents or carers, so that they could discuss participating in the study, and were distributed by the teachers of each participating class a few days before the planned sessions. In cohort 1 , as the participants were under 16 years old, parental consent was obtained and students gave their own assent in the data collection session. Participants in cohorts 2 and 3 were over 16 and gave their own informed consent. Most of the sessions for cohorts 1 and 2 took place during normal lesson time, and a few took place before lessons started, or at lunchtime. Cohort 3 participated in sessions outside their timetabled lectures and seminars.

All students were given a booklet in which to record their responses. The researcher gave the students the instructions for each task using PowerPoint slides and a standard script. All the stimuli, such as the SPM problems and the incomplete sentences, were included in the response booklets, apart from the three examples for the drawing task (which were presented on the slides) and the number sequences for the digit span task (which the researcher read 
aloud). The testing session was 1-11/4 hours in duration. Due to timetabling constraints, it was not possible to have all students complete all of the tasks (Table 1 shows the sample size for each task). Students first provided some demographic information, and then their current studies and/or past school results, the wellbeing measures, the creativity measures, the SPM short form, the BFI-10, the Hayling Sentence Completion Task, the digit span task, and the leisure questionnaire ${ }^{\mathrm{i}}$. Participants who had not been studying at an English-speaking school for five years or more were excluded from the sample. This was to ensure adequate language proficiency to be able to carry out the tasks and accurately understand task instructions.

Data was collected from 437 participants. Fifteen participants were excluded from cohort 2 as they were older than 18 , so that cohort 2 and cohort 3 did not overlap in age. A further 10 participants were excluded as their SPM scores were below the range that could be translated to IQ using Jensen et al.'s (1988) table (cohort 1=6, cohort 2=3, cohort 3=1), and a further 3 were excluded as they generated an average of less than one response for each item in the AUT (cohort 1=2, cohort 3=1). The final sample consisted of 409 participants (cohort $1=134$, cohort $2=204$, cohort $3=71$ ). See Table 1 for the descriptive statistics of the variables.

\section{Approach to statistical analysis}

Data analysis was carried out using IBM SPSS Statistics version 24, and the JASP software version 0.8.6.0 (JASP Team, 2018). Interpretation of $p$-values within a traditional frequentist framework does not allow researchers to determine the relative strength of the evidence for a null or alternate hypothesis, or whether a non-significant $p$ value represents a null effect or insensitive data (Kruschke \& Liddell, 2018; Lakens, McLatchie, Isager, Scheel, \& Dienes, 2018; Quintana \& Williams, 2018). Bayesian hypothesis testing offers a useful 
Table 1

Summary of sample sizes, means and SDs of the creativity variables, individual differences and contextual factors, and wellbeing variables

\begin{tabular}{|c|c|c|c|c|c|c|c|c|c|c|c|c|}
\hline \multirow[b]{2}{*}{ Variable } & \multicolumn{3}{|c|}{ Whole dataset } & \multicolumn{3}{|c|}{ Cohort 1 (age: 14-15) } & \multicolumn{3}{|c|}{ Cohort 2 (age: 16-17) } & \multicolumn{3}{|c|}{ Cohort 3 (age: 18-20) } \\
\hline & $\mathrm{N}$ & Mean & SD & $\mathrm{N}$ & Mean & SD & $\mathrm{N}$ & Mean & SD & $\mathrm{N}$ & Mean & SD \\
\hline AUT Fluency & 407 & 4.36 & 1.67 & 132 & 4.09 & 1.73 & 204 & 4.43 & 1.71 & 71 & 4.64 & 1.36 \\
\hline AUT Overall originality & 407 & 6.42 & 2.08 & 132 & 6.55 & 2.40 & 204 & 6.21 & 1.88 & 71 & 6.79 & 1.94 \\
\hline AUT Peak originality & 407 & 6.01 & 3.64 & 132 & 5.86 & 3.71 & 204 & 5.89 & 3.64 & 71 & 6.65 & 3.51 \\
\hline $\mathrm{OKC}$ & 390 & 1.23 & 0.95 & 129 & 1.26 & 0.97 & 195 & 1.31 & 0.92 & 66 & 0.97 & 0.96 \\
\hline Openness & 409 & 6.56 & 2.07 & 134 & 6.75 & 1.91 & 204 & 6.44 & 2.23 & 71 & 6.51 & 1.89 \\
\hline IQ & 381 & 105.48 & 7.88 & 114 & 104.37 & 8.33 & 196 & 105.76 & 7.62 & 71 & 106.48 & 7.75 \\
\hline LDSF & 344 & 6.88 & 1.34 & 79 & 7.03 & 1.44 & 196 & 6.79 & 1.27 & 69 & 6.99 & 1.40 \\
\hline LDSB & 267 & 6.22 & 1.47 & 34 & 6.76 & 1.30 & 167 & 6.08 & 1.53 & 66 & 6.30 & 1.34 \\
\hline LDSS & - & - & - & - & - & - & - & - & - & 68 & 6.24 & 1.27 \\
\hline Creative hobbies & 281 & 5.74 & 6.51 & 60 & 7.38 & 7.97 & 150 & 5.87 & 6.34 & 71 & 4.08 & 5.03 \\
\hline
\end{tabular}


alternative, particularly when it comes to interpreting the relative support for a null model against an alternative model (Lakens et al., 2018; Quintana \& Williams, 2018). The JASP software package (JASP Team, 2018) offers Bayesian alternatives to many of the most commonly used inferential tests. In this results section, we have compared the results of the frequentist statistical test with the Bayesian alternative, when there was a Bayesian alternative available within JASP.

The data were analysed using linear regression, logistic regression, and ANOVA. For the regressions, we have compared the frequentist models to the Bayesian regression analysis which presents the results of all possible combinations of the covariates. For the Bayesian regression models, we used a Jeffreys-Zellner-Siow prior with a r scale of 0.354 . For the comparisons between the age groups, frequentist and Bayesian ANOVAs were used to compare the creative potential and predictor variables across the cohorts. The Bayesian ANOVA used the JASP default $r$ scale fixed effects prior width of 0.5 for the prior distribution. We selected a Bayes factor threshold of 3 (and its inverse), as this closely corresponds to a $p$ value of .05 (Wetzels et al., 2011). A Bayes factor of 3 suggests that an alternative model is 3 times more favoured than a null model, given the data ${ }^{\text {ii }}$.

The analysis reported in this paper was run for all ages 14-20 years. Analysis by each age cohort separately is reported in the supplemental materials in Tables S5-7. ${ }^{\text {iii }}$

\section{Results}

The aim of the study was to explore the predictors of creative potential in young people aged 14-20. It included both individual factors, specifically intelligence, personality and executive functions, and contextual factors, specifically leisure activities such as 
engagement in creative hobbies, and sports. The results of the whole cohort analysis are presented in the first section. The second section explores whether creative potential varied across the three age groups included in the study.

\section{Predictors of creativity in young people}

In order to identify predictors for the multiple regressions, simple linear regressions were run for each of the predictor variables and outcome variables, and $p$-values were adjusted to correct for multiple tests using a Bonferroni correction (see Table 2 for a summary). Based on the results, two significant predictors were identified: openness to aesthetic and imaginative experience (individual factor; hereafter referred to as openness) and engagement in creative hobbies (contextual factor). A third predictor, IQ (individual factor), was not significant after adjusting for multiple tests, but was retained because much previous research has supported a positive relationship between creativity and intelligence, although effect sizes have varied depending on the statistical and scoring methods (Benedek et al., 2014; Jauk et al., 2014; Silvia, 2008a, 2008b). Multiple regressions were run to examine the effect of these predictors on creative potential (see Table 3 for a summary of the frequentist multiple regressions and Table 4 for a summary of the Bayesian multiple regressions).

To summarise the results of the frequentist analysis, all the predictor variables had an influence on divergent thinking scores, but to a different extent for different outcome variables (see Table 3). The analysis showed that openness predicted creative potential when measured by fluency and overall originality, and most strongly when measured by peak originality (or the propensity to generate highly unusual responses), but only at the level of a trend for OKC. Moreover, IQ and creative hobbies contributed to the prediction of peak originality. 
Table 2

Summary of Simple Regressions to Identify Predictors of Creativity Variables, $p$ values

\begin{tabular}{lcccc}
\hline \multicolumn{1}{c}{ Variable } & Fluency & Originality & $\begin{array}{c}\text { Peak } \\
\text { Originality }\end{array}$ & OKC \\
\hline Openness & $.000^{\mathrm{a}}$ & $.000^{\mathrm{a}}$ & $.000^{\mathrm{a}}$ & $.004^{\mathrm{a}}$ \\
IQ & .165 & .393 & .012 & .766 \\
LDSF & .918 & .655 & .550 & .440 \\
LDSB & .149 & .936 & .684 & .629 \\
Creative hobbies & $.002^{\mathrm{a}}$ & .190 & $.000^{\mathrm{a}}$ & .287 \\
Sports & .107 & .637 & .225 & .653 \\
\hline
\end{tabular}

Note: $p$ values are uncorrected. ${ }^{a}$ indicates $p$ values that remain significant following correction for multiple tests.

Results from the Bayesian analysis allow us to examine the effect of these predictors further. Bayesian regression analysis in JASP shows the regression models with all possible combinations of the predictors. The results presented in Table 4 show that multiple models

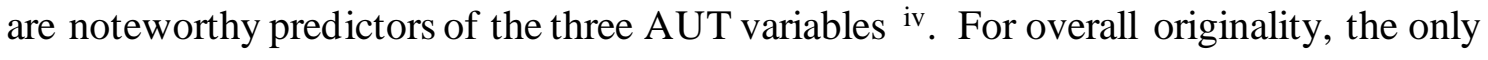
noteworthy predictor was openness. For fluency and peak originality, multiple models involving both individual and contextual variables were good predictors of these aspects of creative potential. For fluency, the strongest model was that which included only openness as a predictor, whereas for peak originality, the strongest model was one which included all three predictors, openness, IQ, and creative hobbies.

\section{Differences between the Age Cohorts in Creativity and its Predictors}

Looking first at the measures of creative potential, there were no differences between the cohorts in overall originality or peak originality, and this was supported by both the 
Table 3

Summary of the Frequentist Multiple Regressions Predicting Creativity from Openness, IQ, and Engagement in Creative Hobbies

\begin{tabular}{|c|c|c|c|c|c|c|c|c|}
\hline \multirow[b]{2}{*}{ Predictor } & \multicolumn{2}{|c|}{ Fluency } & \multicolumn{2}{|c|}{ Overall Originality } & \multicolumn{2}{|c|}{ Peak Originality } & \multicolumn{2}{|r|}{$\mathrm{OKC}$} \\
\hline & B & $95 \% \mathrm{CI}$ & B & $95 \% \mathrm{CI}$ & B & $95 \% \mathrm{CI}$ & B & $95 \% \mathrm{CI}$ \\
\hline Openness & $0.19 * * *$ & {$[0.09,0.29]$} & $0.15^{*}$ & {$[0.02,0.28]$} & $0.39 * *$ & {$[0.17,0.61]$} & $1.14 \dagger$ & {$[1.00,1.30]$} \\
\hline IQ & 0.01 & {$[-0.02,0.03]$} & 0.02 & {$[-0.01,0.05]$} & $0.06^{*}$ & {$[0.00,0.11]$} & .99 & {$[0.96,1.02]$} \\
\hline Creative hobbies & 0.02 & {$[-0.01,0.06]$} & 0.01 & {$[-0.03,0.05]$} & $0.08 *$ & {$[0.01,0.15]$} & 1.00 & {$[0.96,1.05]$} \\
\hline$R^{2}$ & .09 & & .03 & & .11 & & .03 & \\
\hline$F$ & 8.93 & & 3.02 & & 10.98 & & & \\
\hline$p$ & $<.001$ & & .030 & & $<.001$ & & .165 & \\
\hline
\end{tabular}

Note: The table reports the results of linear regressions for fluency, overall originality and peak originality, $\mathrm{N}=271$. For OKC the results of logistic regression are reported with Nagelkerke's $R^{2}, N=262, \chi^{2}=5.10$.

$\dagger p<.10 . * p<.05 . * * p<.01 . * * * p<.001$.

Table 4

Summary of the Bayesian Multiple Regressions Predicting Creative Potential from Openness, IQ, and Engagement in Creative Hobbies

\begin{tabular}{|c|c|c|c|c|c|c|c|c|}
\hline \multicolumn{3}{|l|}{ Fluency } & \multicolumn{3}{|l|}{ Overall Originality } & \multicolumn{3}{|l|}{ Peak Originality } \\
\hline Model predictors & $\mathrm{BF}_{10}$ & $\mathrm{R}^{2}$ & Model predictors & $\mathrm{BF}_{10}$ & & Model predictors & $\mathrm{BF}_{10}$ & $\mathrm{R}^{2}$ \\
\hline Null model & 1.00 & .00 & Null model & 1.00 & .00 & Null model & 1.00 & .00 \\
\hline Openness & 8575.61 & .08 & Openness & 4.85 & .03 & Openness + IQ + Creative hobbies & 13513.90 & .11 \\
\hline Openness + Creative hobbies & 3845.16 & .09 & Openness + IQ & 1.62 & .03 & Openness + Creative hobbies & 9901.73 & .10 \\
\hline Openness + IQ & 1733.28 & .08 & Openness + Creative hobbies & 1.00 & .03 & Openness & 8406.81 & .08 \\
\hline Openness + IQ + Creative hobbies & 1000.70 & .09 & Openness + IQ + Creative hobbies & 0.42 & .03 & Openness + IQ & 7982.03 & .10 \\
\hline Creative hobbies & 15.04 & .04 & Creative hobbies & 0.37 & .01 & IQ + Creative hobbies & 233.52 & .07 \\
\hline IQ + Creative hobbies & 5.37 & .04 & IQ & 0.34 & .01 & Creative hobbies & 83.09 & .05 \\
\hline IQ & 0.26 & .01 & IQ + Creative hobbies & 0.18 & .02 & IQ & 2.02 & .02 \\
\hline
\end{tabular}


Table 5

Differences between the three cohorts for creative potential and predictor variables using null hypothesis significant testing (NHST) and Bayesian analyses

\begin{tabular}{|c|c|c|c|}
\hline Variable & NHST & Bayes & Factors $\left(\mathrm{BF}_{10}\right)$ \\
\hline Average fluency & Non-significant $(F(2,404)=2.92, p=.055)$ & 0.44 & Anecdotal support for the null hypothesis \\
\hline Overall originality & Non-significant $(F(2,180.67)=2.69, p=.070)^{*}$ & 0.28 & Moderate support for the null hypothesis \\
\hline Peak originality & Non-significant $(F(2,404)=1.31, p=.270)$ & 0.10 & Moderate support for the null hypothesis \\
\hline Raw OKC & Significant $(F(2,387)=3.22, p=.041)$ & 0.58 & Anecdotal support for the null hypothesis \\
\hline Openness & Non-significant $(F(2,195.44)=1.00, p=.370)^{*}$ & 0.07 & Strong support for the null hypothesis \\
\hline IQ & Non-significant $(F(2,378)=1.84, p=.161)$ & 0.17 & Moderate support for the null hypothesis \\
\hline LDSF & Non-significant $(F(2,341)=1.12, p=.329)$ & 0.10 & Moderate support for the null hypothesis \\
\hline LDSB & Significant $(F(2,264)=3.21, p=.042)$ & 0.83 & Anecdotal support for the null hypothesis \\
\hline Creative hobbies & Significant $(F(2,278)=4.35, p=.014)$ & 1.91 & Anecdotal support for the alternate hypothesis \\
\hline
\end{tabular}

Note: *Welch's $F$. 
frequentist and Bayesian analysis (all $p>.05, \mathrm{BF}_{10}<0.33$, see Table 5). For fluency, there was no support for cohort-based differences as the frequentist analysis suggested that there was no significant difference between the cohorts $(p=.055)$ and the results of the Bayesian analysis provided anecdotal support for the null hypothesis $\left(\mathrm{BF}_{10}=0.44\right)$. A comparison of raw OKC scores across the cohorts produced mixed results and was inconclusive: the frequentist analysis indicated that there was a significant difference between the cohorts $(F$ $(2,387)=3.22, p=.041)^{\mathrm{v}}$ but the results of the Bayesian analysis provided anecdotal support for the null hypothesis $\left(\mathrm{BF}_{10}=0.58\right)$. In summary, the three cohorts were not found to be consistently and significantly different in any aspect of creative ideation.

Looking next at the individual predictors of creative potential, there were no differences between the cohorts in openness, IQ and longest digit span forwards score (LDSF) which measured short term memory, and this was supported by both the frequentist and Bayesian analysis (all $p>.05, \mathrm{BF}_{10}<0.33$, see Table 5). The evidence was inconclusive as to whether there was a difference in longest digit span backwards (LDSB) scores, a measure of working memory, between the cohorts: it was supported by the frequentist analysis $(p=.042)^{\mathrm{vi}}$, but the Bayes factor was inconclusive, as it was close to $1\left(\mathrm{BF}_{10}=0.83\right)$. Looking at the contextual predictor, engagement in creative hobbies, the finding that participation declined with age was significantly supported by the frequentist analysis $(p=$ $.014)^{\mathrm{vii}}$, and there was a significant linear trend $\left(F(1,278)=8.68, p=.003, \eta^{2}=.03\right)$ which indicated that engagement in creative hobbies declined across the age groups, but there was only anecdotal evidence for the same from the Bayesian analysis $\left(\mathrm{BF}_{10}=1.91\right)$. To summarise, there were no differences between the cohorts in openness, IQ, and the digit span scores, but engagement in creative hobbies declined across the cohorts (see Figure 1). 


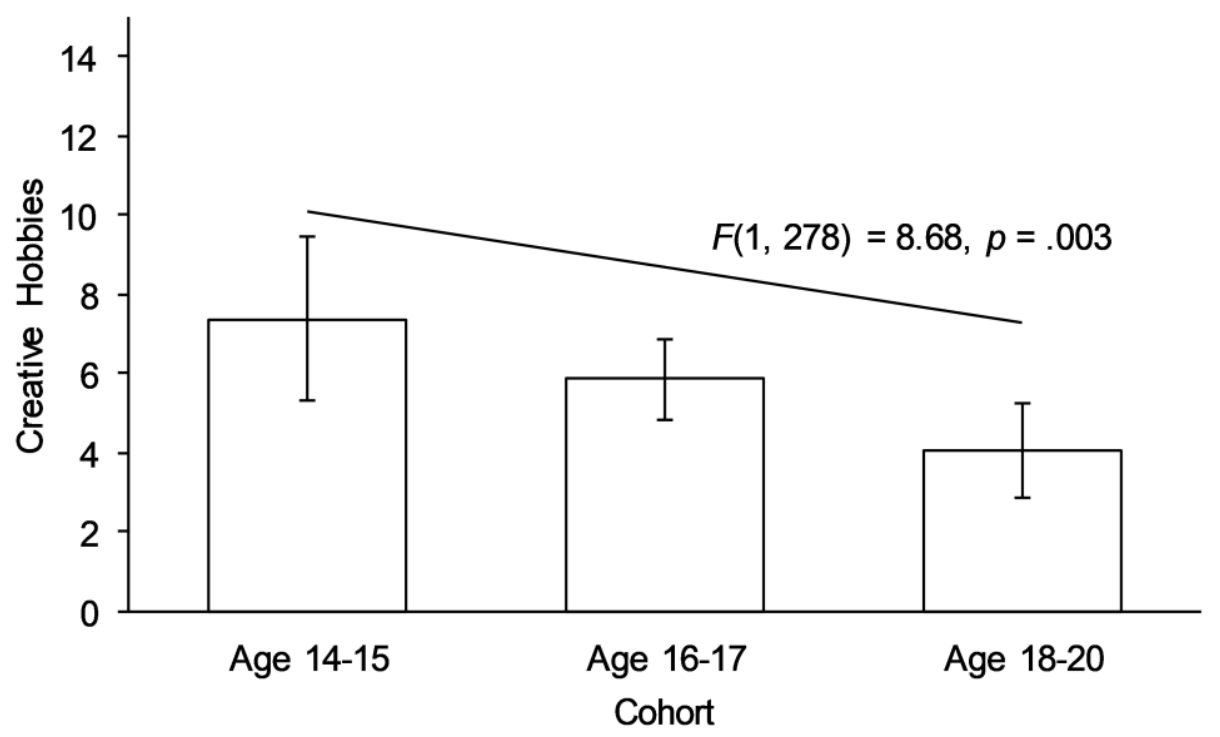

Figure 1: Mean weekly engagement in creative hobbies by cohort (number of days per week). Error bars represent the $95 \%$ confidence interval.

\section{Discussion}

This study examined predictors of creativity, specifically personality traits in the form of openness to aesthetic and imaginative experience and contextual factors in the form of engagement in creative hobbies, in young people aged 14-20. To summarise the results of the regression analysis, openness consistently predicted creative potential as measured by fluency, overall originality and peak originality. The role of openness in predicting such aspects of divergent thinking is in line with the results from several other studies on adult populations (Jauk et al., 2014; McCrae, 1987; Puryear et al., 2017). Only a few studies have examined the same in populations below university age (Niu, 2007; Shi, Dao \& Lu, 2016). McCrae (1987) proposed three possible explanations for the relationship between openness and divergent thinking: first, that people high in openness may be more engaged by divergent thinking tasks; second, that they may develop divergent thinking skills through practice, and third, that divergent thinking may facilitate interests in varied experience. 
The present findings add to the debate on the association between intelligence and creative potential. IQ did not predict fluency or overall originality, but the Bayesian regressions suggested that it did notably contribute to the prediction of peak originality, or the generation of highly original responses. This contrasts with other research that found a relationship between intelligence and fluency and originality (Furnham, 2015; Kandler et al., 2016; Karwowski et al., 2016) but is in line with the findings of Jauk et al.'s (2013) study which found a relationship between intelligence and creative potential, when specifically taking into consideration the number of creative ideas that were generated. Jauk et al.'s study also found a threshold IQ score of 120 for this relationship and a lower threshold of 85 for the relationship between intelligence and fluency. The present study employed a short form SPM and translated the results to IQ scores (Jensen et al., 1988), which limited IQ scores to a range from 85 to 117 . This may explain why IQ did not predict fluency in this study as other studies that have found that intelligence predicted divergent thinking scores have used full form tests of IQ (Furnham, 2015; Runco \& Albert, 1986; Silvia, 2008a).

In our study, we did not investigate an interaction between openness and intelligence, but recent research suggests a role for the interaction in predicting creative achievement, such that the relationship between intelligence and creative achievement is stronger in those who are higher in openness (Harris et al., 2019). Although that study only investigated creative achievement, the authors suggested that their conditional threshold hypothesis may also apply to measures of creative potential, which would be an interesting question for future research.

There was also support for engagement in creative hobbies as a predictor of one of the measures of creative potential, peak originality. The effect of engagement in creative hobbies on creative potential has not been studied extensively. Cotter et al. (2016) studied the relationship between extracurricular activities and creativity in college students and found that involvement in arts clubs did not predict divergent thinking although it did predict some 
forms of creativity, such as caption and performance creativity. There is some overlap between the creative hobbies included in the leisure questionnaire and the way in which everyday creativity and creative activity has been measured in adult samples. A positive relationship has been found between openness and creative activity (Jauk et al., 2014; Wolfradt \& Pretz, 2001) as well as between openness and everyday creative engagement (Conner \& Silvia, 2015; Silvia et al., 2014). Engagement in creative hobbies in this study was also positively correlated with openness (see Table S8 in the supplemental material). This may explain why creative hobbies were not a stronger predictor of creative potential in addition to openness.

To sum up, the influence of the individual and contextual predictors differed for the various measures of creative potential. Openness was the most consistent predictor, but there was also support for intelligence and engagement in creative hobbies as noteworthy additional predictors of peak originality (or the generation of highly original responses) in particular. It should be noted that the BFI-10 (Rammstedt \& John, 2007) contains only two items for the two aspects of the personality trait of openness. The item '... has lots of artistic interests' captures the 'openness' aspect of openness to experience, which reflects engagement with aesthetics, perception and fantasy. The item '...has an active imagination' correlates almost equally with both the 'openness' aspect, and the 'intellect' aspect of engagement with abstract and semantic information (DeYoung, Quilty \& Peterson, 2007). Openness to experience as operationalised in this study may therefore be considered to focus on the aesthetic and imaginative aspects and underrepresent the 'intellect' aspect of the trait. Intellect is associated with non-verbal intelligence (DeYoung, Quilty, Peterson \& Gray, 2014) and with working memory (DeYoung, Shamosh, Green, Braver \& Gray, 2009) which were represented by IQ and digit span tasks in this study. Note that we found some support 
for IQ as a predictor of creative potential in the form of peak originality, but none for working memory.

The study also examined differences in creativity and individual and contextual factors. There were no differences in creative ideation between the three age groups, and these findings are consistent with the work of Wu, Cheng, Ip, and McBride-Chang (2005) who found no differences in tests of verbal divergent thinking between two age groups, grade 6 and university students aged 19-22. It is also broadly consistent with the work of Kleibeuker et al. (2013) who found no differences in fluency across four age groups, 12/13, $15 / 16,18 / 19$ and 25-30, although they did find a difference in originality between their 12/13 and 15/16 groups and the young adult 25-30 group. Other studies which used the Test for Creative Thinking - Drawing Production (TCT-DP; Urban, 2005) found a dip in creativity during adolescence (Gralewski et al., 2016; Jastrzębska \& Limont, 2017), which was not seen here in the verbal divergent thinking task. Wu et al. (2005) suggested that the level of knowledge and language ability required for the AUT may not differentiate the two groups in their study, and Kleibeuker et al. (2013) suggested that the ability to generate multiple ideas is fully developed by early adolescence. The greater originality that they found in the young adult age group, older than the oldest age group in this study, may be due to access to more diverse experiences, and to a greater ability to flex between analytical and associative processing (Kleibeuker et al., 2013).

We found no differences between the cohorts in the individual predictors of creativity, openness, IQ, and the digit span tasks, but we did find a difference in the contextual predictor, engagement in creative hobbies. We did not explore further in this study why this might be the case. One possible explanation is that the decline in engagement in creative hobbies reflects a difference in the samples, as the older age group was made up of university students, and not all of the 14-15- and 16-17-year olds may go on to university. However, 
other factors may be relevant in these age groups. For example, increasing academic pressure, work, and living away from home for the first time may affect both the time and resources available for such hobbies, and provide alternative explanations.

Although a lot of research has looked at profiles of engagement in extracurricular activities and leisure interests such as physical activity and sedentary behaviour in adolescents and young people, only a limited amount of research has examined participation in the arts or creative hobbies (Auhuber, Vogel, Grafe, Kiess, \& Poulain, 2019). It would be informative to see whether engagement in creative hobbies changes with age, particularly if it is associated with differences in creative potential. This is planned for the second phase of the current study where participants from the first phase will be followed up after 18-24 months for retesting.

\section{Limitations of the study}

The data were collected in a group setting with written responses, as this was practical for recruiting participants from schools and colleges without disrupting the students' timetables over a long period. It also enabled collection of a larger sample size than would have been possible with one-to-one data collection. It may however have affected the sensitivity of the measures of executive functions. The Hayling Sentence Completion Task is usually administered on a one to one basis with verbal responses. The results were higher than the published norms (Burgess \& Shallice, 1997) and did not discriminate, and so they were excluded from further analysis. The digit span task was selected to measure working memory, as it could be administered in a group setting, but it is possible that the use of written rather than verbal responses affected the sensitivity of the scores. In terms of sampling, cohort 3 was recruited from higher education students at a single university. Although we did not expect any differences in creative potential in relation to the destination 
after age 18 , it should be borne in mind that only $51 \%$ of young people go to university after leaving school or college in the UK (Department for Education, 2018). The second phase of this study will follow up with participants from phase 1 after 18-24 months. We expect that the participants from cohort 2 will access a wider set of destinations, so it will be possible to investigate this within the second phase. The sample was predominantly female, particularly in cohort 3, and although we did not expect to find any differences in relation to gender it is possible that there may have been some differences to explore in the results had there been a greater proportion of male participants.

\section{Conclusions}

The study has employed a cross-sectional design to examine the predictors of creative potential in young people aged 14-20 and has evaluated the relative influence of both individual factors, specifically intelligence, personality, and executive functions, and contextual factors, specifically leisure activities such as engagement in creative hobbies and sports. It has used a combination of frequentist and Bayesian approaches to understand the influence of these factors. The results showed that specific individual factors (in the form of openness and IQ) and specific contextual factors (in the form of engagement in creative hobbies) all had an influence on divergent thinking, but to a different extent for different outcome variables. There were no differences in the three age groups in creative potential, openness or IQ, but engagement in creative hobbies was lower in the 18-20 age group than the 14-15 age group. By identifying the differential impact of individual and environmental factors on different facets of creative potential during development, the insights from this novel study using an original data-analytic approach constitute a foundational step for future explorations of how to optimally nurture creativity over the lifespan. 


\section{References}

Abraham, A. (2014a). Is there an inverted-U relationship between creativity and psychopathology? Frontiers in Psychology, 5(750). doi:10.3389/fpsyg.2014.00750

Abraham, A. (2014b). Neurocognitive mechanisms underlying creative thinking: Indications from studies of mental illness. In J. C. Kaufman (Ed.), Creativity and mental illness (pp. 79-101). Cambridge, UK: Cambridge University Press.

Abraham, A., Asquith, S., Ahmed, H., \& Bourisly, A. K. (2019). Comparing the efficacy of four brief inductions in boosting short-term creativity. Journal of Cognitive Enhancement, 3(1), 85-93. doi:10.1007/s41465-018-0085-0

Abraham, A., \& Windmann, S. (2007). Creative cognition: The diverse operations and the prospect of applying a cognitive neuroscience perspective. Methods, 42(1), 38-48. doi:10.1016/j.ymeth.2006.12.007

Ábrahám, J., Velenczei, A., \& Szabo, A. (2012). Perceived determinants of well-being and enjoyment level of leisure activities. Leisure Sciences, 34(3), 199-216. doi:10.1080/01490400.2012.669677

Amabile, T. M. (1996). Creativity in Context. Boulder, CO: Westview.

Auhuber, L., Vogel, M., Grafe, N., Kiess, W., \& Poulain, T. (2019). Leisure activities of healthy children and adolescents. International Journal of Environmental Research and Public Health, 16(12), 2078. doi:10.3390/ijerph16122078

Badia, M., Orgaz, M. B., Verdugo, M. A., \& Ullan, A. M. (2013). Patterns and determinants of leisure participation of youth and adults with developmental disabilities. Journal of Intellectual Disability Research, 57(4), 319-332. doi:10.1111/j.13652788.2012.01539.x 
Barbot, B., Lubart, T. I., \& Besançon, M. (2016). "Peaks, slumps, and bumps": Individual differences in the development of creativity in children and adolescents. New Directions for Child \& Adolescent Development, 151, 33-45. doi:10.1002/cad.20152

Bartko, W. T., \& Eccles, J. S. (2003). Adolescent participation in structured and unstructured activities: A person-oriented analysis. Journal of Youth and Adolescence, 32(4), 233241. doi:10.1023/A:1023056425648

Batey, M., Chamorro-Premuzic, T., \& Furnham, A. (2010). Individual differences in ideational behavior: Can the Big Five and psychometric intelligence predict creativity scores? Creativity Research Journal, 22(1), 90-97. doi: 10.1080/10400410903579627

Benedek, M., Franz, F., Heene, M., \& Neubauer, A. C. (2012). Differential effects of cognitive inhibition and intelligence on creativity. Personality and Individual Differences, 53, 480-485. doi:10.1016/j.paid.2012.04.014

Benedek, M., Jauk, E., Sommer, M., Arendasy, M., \& Neubauer, A. C. (2014). Intelligence, creativity, and cognitive control: The common and differential involvement of executive functions in intelligence and creativity. Intelligence, 46, 73-83. doi:10.1016/j.intell.2014.05.007

Besançon, M., \& Lubart, T. (2008). Differences in the development of creative competencies in children schooled in diverse learning environments. Learning and Individual Differences, 18(4), 381-389. doi:10.1016/j.lindif.2007.11.009

Bilker, W. B., Hansen, J. A., Brensinger, C. M., Richard, J., Gur, R. E., \& Gur, R. C. (2012). Development of abbreviated nine-item forms of the Raven's Standard Progressive Matrices Test. Assessment, 19(3), 354-369. doi:10.1177/1073191112446655 
Brailovskaia, J., \& Margraf, J. (2018). What does media use reveal about personality and mental health? An exploratory investigation among German students. Plos One, 13(1). doi:10.1371/journal.pone.0191810

Burgess, P. W., \& Shallice, T. (1997). The Hayling and Brixton Tests. London, UK: Pearson.

Carson, S. H. (2011). Creativity and psychopathology: A shared vulnerability model. Canadian Journal of Psychiatry, 56(3), 144-153. doi:10.1177/070674371105600304

Carson, S. H., Peterson, J. B., \& Higgins, D. M. (2003). Decreased latent inhibition is associated with increased creative achievement in high-functioning individuals. Journal of Personality and Social Psychology, 85(3), 499-506. doi:10.1037/00223514.85.3.499

Conner, T. S., \& Silvia, P. J. (2015). Creative days: A daily diary study of emotion, personality, and everyday creativity. Psychology of Aesthetics, Creativity, and the Arts, 9(4), 463-470. doi:10.1037/aca0000022

Costa, P. T., \& McCrae, R. R. (1985). The NEO personality inventory manual. Odessa, FL: Psychological Assessment Resources.

Cotter, K. N., Pretz, J. E., \& Kaufman, J. C. (2016). Applicant extracurricular involvement predicts creativity better than traditional admissions factors. Psychology of Aesthetics, Creativity, and the Arts, 10(1), 2-13. doi:10.1037/a0039831

Davis, C. D., Kaufman, J. C., \& McClure, F. H. (2011). Non-cognitive constructs and selfreported creativity by domain. Journal of Creative Behavior, 45(3), 188-202. doi:10.1002/j.2162-6057.2011.tb01426.x

De Dreu, C. K. W., Nijstad, B. A., Baas, M., Wolsink, I., \& Roskes, M. (2012). Working memory benefits creative insight, musical improvisation, and original ideation 
through maintained task-focused attention. Personality \& Social Psychology Bulletin, 38(5), 656-69. doi:10.1177/0146167211435795

de Manzano, Ö., \& Ullén, F. (2018). Genetic and environmental influences on the phenotypic associations between intelligence, personality, and creative achievement in the arts and sciences. Intelligence, 69, 123-133. doi:10.1016/j.intell.2018.05.004

Deng, L., Wang, L., \& Zhao, Y. (2016). How creativity was affected by environmental factors and individual characteristics: A cross-cultural comparison perspective. Creativity Research Journal, 28(3), 357-366. doi:10.1080/10400419.2016.1195615

Department for Education. (2018). Destinations of key stage 4 and key stage 5students, England, 2016/17. https://assets.publishing.service.gov.uk/government/uploads/syste m/uploads/attachment_data/file/748199/Destinations_Main_Text_2017.pdf

DeYoung, C. G., Quilty, L. C., \& Peterson, J. B. (2007). Between facets and domains: 10 aspects of the Big Five. Journal of Personality \& Social Psychology, 93(5), 880-896. doi:10.1037/0022-3514.93.5.880

DeYoung, C. G., Quilty, L. C., Peterson, J. B., \& Gray, J. R. (2014). Openness to experience, intellect, and cognitive ability. Journal of Personality Assessment, 96(1), 46-52. doi:10.1080/00223891.2013.806327

DeYoung, C. G., Shamosh, N. A., Green, A. E., Braver, T. S., \& Gray, J. R. (2009). Intellect as distinct from openness: Differences revealed by fMRI of working memory. Journal of Personality \& Social Psychology, 97(5), 883-892.

Diamond, A. (2013). Executive Functions. Annual Review of Psychology, 64(1), 135-168 34p. doi:10.1146/annurev-psych-113011-143750

Erikson, E. H. (1968). Identity, youth, and crisis. New York, NY: Norton. 
Feist, G. J. (1998). A meta-analysis of personality in scientific and artistic creativity.

Personality \& Social Psychology Review, 2(4), 290-309.

doi:10.1207/s15327957pspr0204_5

Feldman, A. F., \& Matjasko, J. L. (2005). The role of school-based extracurricular activities in adolescent development: A comprehensive review and future directions. Review of Educational Research, 75(2), 159-210. doi:10.3102/00346543075002159

Field, A. (2013). Discovering Statistics using IBM SPSS Statistics. London, UK: Sage.

Furnham, A. (2015). The bright and dark side correlates of creativity: Demographic, ability, personality traits and personality disorders associated with divergent thinking. Creativity Research Journal, 27(1), 39-46. doi:10.1080/10400419.2015.992676

Goldstein, T. R. (2011). Correlations among social-cognitive skills in adolescents involved in acting or arts classes. Mind, Brain, and Education, 5(2), 97-103. doi:10.1111/j.1751228X.2011.01115.X

Götz, F. M., Ebert, T., \& Rentfrow, P. J. (2018). Regional cultures and the psychological geography of Switzerland: Person-environment-fit in personality predicts subjective wellbeing. Frontiers in Psychology, 9(APR). doi:10.3389/fpsyg.2018.00517

Gough, H. G. (1979). A creative personality scale for the Adjective Check List. Journal of Personality and Social Psychology, 37(8), 1398-1405. doi:10.1037/00223514.37.8.1398

Gralewski, J., Lebuda, I., Gajda, A., Jankowska, D., M., \& Wiśniewska, E. (2016). Slumps and jumps: Another look at developmental changes in creative abilities. Creativity.3(1), 152-177. doi:10.1515/ctra-2016-0011 
Guilford, J. P. (1966). Measurement and Creativity. Theory Into Practice, 5(4), 185-9. doi:10.1080/00405846609542023

Guilford, J. P. (1967). The nature of human intelligence. London, UK: McGraw-Hill.

Guilford, J. P., Christensen, P. R., Merrifield, P. R., \& Wilson, R. C. (1960). Alternate Uses Manual. Menlo Park, CA: Mind Garden.

Harris, A. M., Williamson, R. L., \& Carter, N. T. (2019). A conditional threshold hypothesis for creative achievement: On the interaction between intelligence and openness. Psychology of Aesthetics, Creativity, and the Arts, 13(3), 322-337. doi:10.1037/aca0000182

He, W.-J., \& Wong, W.-C. (2015). Creativity slump and school transition stress: A sequential study from the perspective of the cognitive-relational theory of stress. Learning and Individual Differences, 43, 185-190. doi:10.1016/j.lind if.2015.08.034

Hong, E., Peng, Y., \& O'Neil, H. F., Jr. (2014). Activities and accomplishments in various domains: Relationships with creative personality and creative motivation in adolescence. Roeper Review, 36(2), 92-103. doi:10.1080/02783193.2014.884199

Hui, A. N. N., He, M. W. J., \& Wong, W. (2019). Understanding the development of creativity across the life span. In J. C. Kaufman \& R. J. Sternberg (Eds.), The Cambridge handbook of creativity (pp. 69-87). Cambridge: Cambridge University Press.

Hunter, S. T., Bedell, K. E., \& Mumford, M. D. (2007). Climate for creativity: A quantitative review. Creativity Research Journal, 19(1), 69-90. doi:10.1080/10400410701277597

JASP Team. (2018). JASP (Version 0.8.6.0). 
Jastrzębska, D., \& Limont, W. (2017). Not only jumps, slumps, but also mini plateau.

Creative potential assessed by the test for creative thinking-drawing production. A cross-sectional study of Polish students aged from 7 to 18. Creativity Research Journal, 29(3), 337-342. doi:10.1080/10400419.2017.1360060

Jauk, E., Benedek, M., Dunst, B., \& Neubauer, A. C. (2013). The relationship between intelligence and creativity: New support for the threshold hypothesis by means of empirical breakpoint detection. Intelligence, 41, 212-221. doi:10.1016/j.intell.2013.03.003

Jauk, E., Benedek, M., \& Neubauer, A. C. (2014). The road to creative achievement: A latent variable model of ability and personality predictors. European Journal of Personality, 28(1), 95-105. doi:10.1002/per.1941

Jeffreys, H. (1961). Theory of probability (3rd ed.). Oxford, UK: Oxford University Press.

Jensen, A. R., Saccuzzo, D. P., \& Larson, G. E. (1988). Equating the Standard and Advanced forms of the Raven Progressive Matrices. Educational and psychological measurement, 48(4), 1091-1095. doi:http://journals.sagepub.com/home/epm

John, O. P., Donahue, E. M., \& Kentle, R. L. (1991). The Big Five Inventory-Versions 4a and 54. Berkeley, CA: University of California, Berkeley, Institute of Personality and Social Research.

Jopp, D. S., \& Hertzog, C. (2010). Assessing adult leisure activities: An extension of a selfreport activity questionnaire. Psychological Assessment, 22(1), 108-120. doi:10.1037/a0017662

Kandler, C., Riemann, R., Angleitner, A., Spinath, F. M., Borkenau, P., \& Penke, L. (2016). The nature of creativity: The roles of genetic factors, personality traits, cognitive 
abilities, and environmental sources. Journal of Personality and Social Psychology, $111(2), 230-249$.

Karwowski, M., Dul, J., Gralewski, J., Jauk, E., Jankowska, D. M., Gajda, A., . . . Benedek, M. (2016). Is creativity without intelligence possible? A Necessary Condition Analysis. Intelligence, 57, 105-117. doi:10.1016/j.intell.2016.04.006

Kaufman, S. B., Quilty, L. C., Grazioplene, R. G., Hirsh, J. B., Gray, J. R., Peterson, J. B., \& Deyoung, C. G. (2016). Openness to experience and intellect differentially predict creative achievement in the arts and sciences. Journal Of Personality, 84(2), 248-58. doi:10.1111/jopy.12156

Kim, K. H. (2005). Can only intelligent people be creative? A meta-analysis. Journal of Secondary Gifted Education, 16(2-3), 57-66. doi:10.4219/jsge-2005-473

Kim, K. H. (2008). Meta-Analyses of the Relationship of Creative Achievement to both IQ and Divergent Thinking Test Scores. Journal of Creative Behavior, 42(2), 106-30.

Kleibeuker, S. W., De Dreu, C. K. W., \& Crone, E. A. (2013). The development of creative cognition across adolescence: Distinct trajectories for insight and divergent thinking. Developmental Science, 16(1), 2-12. doi:10.1111/j.1467-7687.2012.01176.x

Kruschke, J. K., \& Liddell, T. M. (2018). The Bayesian New Statistics: Hypothesis testing, estimation, meta-analysis, and power analysis from a Bayesian perspective. Psychonomic Bulletin \& Review, 25(1), 178-206. doi:10.3758/s13423-016-1221-4

Lakens, D., McLatchie, N., Isager, P. M., Scheel, A. M., \& Dienes, Z. (2018). Improving inferences about null effects with Bayes factors and equivalence tests. The Journals of Gerontology: Series B, gby065-gby. doi:10.1093/geronb/gby065 
Lee, C. S., \& Therriault, D. J. (2013). The cognitive underpinnings of creative thought: A latent variable analysis exploring the roles of intelligence and working memory in three creative thinking processes. Intelligence, 41(5), 306-320. doi:10.1016/j.intell.2013.04.008

Ma, H.-H. (2009). The effect size of variables associated with creativity: A meta-analysis. Creativity Research Journal, 21(1), 30-42. doi:10.1080/10400410802633400

McCrae, R. R. (1987). Creativity, divergent thinking, and openness to experience. Journal of Personality and Social Psychology, 52(6), 1258-1265. doi:10.1037/00223514.52.6.1258

McCrae, R. R., Arenberg, D., \& Costa, P. T. (1987). Declines in divergent thinking with age: Cross-sectional, longitudinal, and cross-sequential analyses. Psychology and Aging, 2(2), 130-137. doi:10.1037/0882-7974.2.2.130

Niu, W. (2007). Individual and environmental influences on Chinese student creativity. Journal of Creative Behavior, 41(3), 151-175. doi:10.1002/j.21626057.2007.tb01286.x

Nusbaum, E. C., \& Silvia, P. J. (2011). Are intelligence and creativity really so different? Fluid intelligence, executive processes, and strategy use in divergent thinking. Intelligence, 39(1), 36-45. doi:10.1016/j.intell.2010.11.002

Passmore, A., \& French, D. (2001). Development and administration of a measure to assess adolescents' participation in leisure activities. Adolescence, 36(141), 67-75.

Plucker, J. A. (1999). Is the proof in the pudding? Reanalyses of Torrance's (1958 to present) longitudinal data. Creativity Research Journal, 12(2), 103-14. 
Puryear, J. S., Kettler, T., \& Rinn, A. N. (2017). Relationships of personality to differential conceptions of creativity: A systematic review. Psychology of Aesthetics, Creativity, and the Arts, 11(1), 59-68. doi:10.1037/aca0000079

Quintana, D. S., \& Williams, D. R. (2018). Bayesian alternatives for common null-hypothesis significance tests in psychiatry: a non-technical guide using JASP. BMC Psychiatry, 18(1), 178. doi:10.1186/s12888-018-1761-4

Rammstedt, B., \& John, O. P. (2007). Measuring personality in one minute or less: A 10-item short version of the Big Five Inventory in English and German. Journal of Research in Personality, 41(1), 203-212. doi:10.1016/j.jrp.2006.02.001

Raven, J. C., Court, J. H., \& Raven, J. (1995). Manual for Raven's Progressive Matrices and Vocabulary Scales. Oxford, England: Oxford Psychologists Press.

Reiter-Palmon, R., Forthmann, B., \& Barbot, B. (2019). Scoring divergent thinking tests: A review and systematic framework. Psychology of Aesthetics, Creativity, and the Arts, 13(2), 144-52. doi:10.1037/aca0000227

Runco, M. A., \& Acar, S. (2012). Divergent thinking as an indicator of creative potential. Creativity Research Journal, 24(1), 66-75. doi:10.1080/10400419.2012.652929

Runco, M. A., Acar, S., \& Cayirdag, N. (2017). A closer look at the creativity gap and why students are less creative at school than outside of school. Thinking Skills and Creativity, 24, 242-249. doi:10.1016/j.tsc.2017.04.003

Runco, M. A., \& Albert, R. S. (1986). The threshold theory regarding creativity and intelligence: An empirical test with gifted and non-gifted children. Creative Child and Adult Quarterly, 11, 212-218. 
Runco, M. A., \& Jaeger, G. J. (2012). The standard definition of creativity. Creativity Research Journal, 24(1), 92-6. doi:10.1080/10400419.2012.650092

Runco, M. A., Okuda, S. M., \& Thurston, B. J. (1987). The psychometric properties of four systems for scoring divergent thinking tests. Journal of Psychoeducational Assessment, 5(2), 149-156. doi:10.1177/073428298700500206

Shi, B., Dai, D. Y.,\& Lu, Y. (2016). Openness to experience as a moderator of the relationship between intelligence and creative thinking: A study of chinese children in urban and rural areas. Frontiers in Psychology, 7, 264. doi:10.3389/fpsyg.2016.00641

Silvia, P. J. (2008a). Another look at creativity and intelligence: Exploring higher-order models and probable confounds. Personality and Individual Differences, 44, 1012-21. doi:10.1016/j.paid .2007 .10 .027

Silvia, P. J. (2008b). Creativity and intelligence revisited: A latent variable analysis of Wallach and Kogan (1965). Creativity Research Journal, 20(1), 34-39. doi:10.1080/10400410701841807

Silvia, P. J., Beaty, R. E., Nusbaum, E. C., Eddington, K. M., Levin-Aspenson, H., \& Kwapil, T. R. (2014). Everyday creativity in daily life: An experience-sampling study of 'little c' creativity. Psychology of Aesthetics, Creativity, and the Arts, 8(2), 183-188. doi:10.1037/a0035722

Smeekens, B. A., \& Kane, M. J. (2016). Working memory capacity, mind wandering, and creative cognition: An individual-differences investigation into the benefits of controlled versus spontaneous thought. Psychology of Aesthetics, Creativity, and the Arts, 10(4), 389-415. doi:10.1037/aca0000046 
Smith, G. J. W., \& Carlsson, I. (1983). Creativity in early and middle school years. International Journal of Behavioral Development, 6(2), 167-195. Retrieved from https://journals.sagepub.com/home/jbd

Smith, S. M., Ward, T. B., \& Schumacher, J. S. (1993). Constraining effects of examples in a creative generation task. Memory \& Cognition, 21(6), 837-845. doi:10.3758/BF03202751

Sternberg, R. J., \& Lubart, T. I. (1992). Buy low and sell high: An investment approach to creativity. Current Directions in Psychological Science, 1(1), 1-5. doi:10.1111/14678721.ep10767737

Sternberg, R. J., \& Lubart, T. I. (1996). Investing in creativity. The American Psychologist, 51(7), 677-688. doi:10.1037/0003-066X.51.7.677

Torrance, E. P. (1968). A longitudinal examination of the fourth grade slump in creativity. Gifted Child Quarterly, 12(4), 195-199. doi:http://journals.sagepub.com/home/gcq

Urban, K. K. (2005). Assessing creativity: The Test for Creative Thinking-Drawing Production (TCT-DP). International Education Journal, 6(2), 272-280. doi:https://openjournals.library.sydney.edu.au/index.php/IEJ/index

Wechsler, D. (2010). WAIS-IV adminstration and scoring manual (UK edition). London, UK: Pearson.

Wetzels, R., Matzke, D., Lee, M. D., Rouder, J. N., Iverson, G. J., \& Wagenmakers, E. J. (2011). Statistical evidence in experimental psychology: An empirical comparison using 855 t tests. Perspectives on Psychological Science, 6(3), 291-298. http://doi.org/10.1177/1745691611406923 
Wetzels, R., van Ravenzwaaij, D., \& Wagenmakers, E.-J. (2015). Bayesian analysis. In R. Cautin \& S. Lilienfeld (Eds.), The encyclopedia of clinical psychology (pp. 274-283). Hoboken, NJ: Wiley-Blackwell.

Whaite, E. O., Shensa, A., Sidani, J. E., Colditz, J. B., \& Primack, B. A. (2018). Social media use, personality characteristics, and social isolation among young adults in the United States. Personality and Individual Differences, 124, 45-50. doi:10.1016/j.paid .2017 .10 .030

Wolfradt, U., \& Pretz, J. E. (2001). Individual differences in creativity: Personality, story writing, and hobbies. European Journal of Personality, 15(4), 297-310. doi:10.1002/per.409

Wu, C. H., Cheng, Y., Ip, H. M., \& McBride-Chang, C. (2005). Age differences in creativity: Task structure and knowledge base. Creativity Research Journal, 17(4), 321-326. doi:10.1207/s15326934crj1704_3

Zabelina, D. L., \& Ganis, G. (2018). Creativity and cognitive control: Behavioral and ERP evidence that divergent thinking, but not real-life creative achievement, relates to better cognitive control. Neuropsychologia, 118(Pt A), 20-28. doi:10.1016/j.neuropsychologia.2018.02.014

Zabelina, D. L., \& Robinson, M. D. (2010). Creativity as flexible cognitive control. Psychology of Aesthetics, Creativity, and the Arts, 4(3), 136-143. doi:10.1037/a0017379 
Footnotes

${ }^{\text {i }}$ Thirty-one students from cohort 2 completed the leisure questionnaire online.

ii Following the proposals made by Wetzels, van Ravenzwaaij, and Wagenmakers (2015), based on Jeffreys (1961), the Bayesian findings were interpreted as follows.

(I) Clear evidence for the alternate hypothesis (extremely strong evidence: $\mathrm{BF}_{10}>$ 100; very strong evidence: 30 - 100; strong evidence: 10 - 30; moderate evidence: $3-10)$

(II) Anecdotal evidence for the alternate hypothesis: $\mathrm{BF}_{10}=1-3$;

(III) No evidence: $\mathrm{BF}_{10}=1$;

(IV) Anecdotal evidence for the null hypothesis: $\mathrm{BF}_{10}=1 / 3-1$;

(V) Clear evidence for the null hypothesis (moderate evidence: $\mathrm{BF}_{10}=1 / 10-1 / 3$; strong evidence: $\mathrm{BF}_{10}=1 / 30-1 / 10$; very strong evidence: $\mathrm{BF}_{10}=1 / 100-1 / 30$; extremely strong evidence: $<1 / 100)$.

iii Please note that when reviewing the cohort level results, it may be important to consider the sample size for cohort 1 (all participants did not complete all of the tasks) and cohort 3 (the smallest cohort), as the sample may be too small for the number of predictors, and this may lead to inflated Rs (Field, 2013).

iv SPSS was used for logistic regression as this was not possible in JASP 0.8.6.0.

${ }^{v}$ Post-hoc tests showed cohort 3 achieving a lower raw OKC score than cohort $2(p=$ .036), with a small to medium effect size (Hedge's $g=0.36$ ). The differences between cohorts 1 and 2 as well as cohorts 1 and 3 were not significant. 
vi Post-hoc tests showed cohort 2 achieving a lower LDSB score than cohort 1 ( $p=$ .040 ), with a small to medium effect size (Hedge's $g=0.47$ ). The differences between cohorts 1 and 3 as well as cohorts 2 and 3 were not significant.

${ }^{\text {vii }}$ Post-hoc tests showed that cohort 1 engaged more in creative hobbies than cohort 3, $p=.018$, with a medium effect size (Hedge's $g=0.51$ ). 